\title{
Spatial Analysis of Breast Cancer Incidence in Iran
}

\author{
Neda Mahdavifar', Reza Pakzad ${ }^{2,3}$, Mahshid Ghoncheh ${ }^{4}$, Iraj Pakzad ${ }^{5,6}$, Asieh \\ Moudi $^{7}$, Hamid Salehiniya ${ }^{3,8 *}$
}

\begin{abstract}
Breast cancer $(\mathrm{BC})$ is the most common cancer in females $(27 \%$ of the total) and the main cause of death $(16 \%)$ due to cancer in women in developed and developing countries. Variations in its incidence rate among geographical areas are due to various contributing factors. Since there have been a lack of studies on this topic in our country, the present spatial analysis of breast cancer incidence in Iran in 2009 was conducted using data from the national cancer registry system. The reported incidences of the disease were standardized according to the World Health Organization population and the direct method. Then data was inserted into the GIS software and finally, using the Hot Spot Analysis (Geties-Ord Gi), high-risk areas were drawn. Provinces with incidences 1.96 SD higher or lower than the national average were considered as hot spots or cold spots, at the significance level of $0.05 \%$. In 2009, a total of 7,582 cases of $\mathrm{BC}$ occurred in Iran. The annual incidence was 33.2 per hundred thousand people. Our study showed that the highest incidence of BC in women occurred in the central provinces of the country, Tehran, Isfahan, Yazd, Markazi and Fars. The results of hot spots analysis showed that the distribution of high-risk BC was focused in central parts of Iran, especially Isfahan province $(\mathrm{p}<0.01)$. The other provinces were not significantly different from the national average. The higher incidence in central provinces may be due to greater exposure to carcinogens in urban areas, a Western lifestyle and high prevalence of other risk factors. Further epidemiological studies about the etiology and early detection of BC are essential.
\end{abstract}

Keywords: Spatial analysis - incidence - epidemiology - breast cancer - Iran

Asian Pac J Cancer Prev, 17, Cancer Control in Western Asia Special Issue, 59-64

\section{Introduction}

Nowadays, cancer is a major health problem in many countries (Keyghobadi et al., 2015; Razi et al., 2015; Zahedi et al., 2015; Zeinalzadeh et al., 2015). Currently cancer is the second leading cause of death in economically developed countries and the third leading cause of death in developing countries (Garcia et al., 2007; Almasi et al., 2015). Breast cancer (BC) is the most common cancer ( $27 \%$ of all cancers) and is the main cause of death $(16 \%)$ due to cancer in women in developed countries and in developing ones (Ghoncheh et al., 2015; Payandeh et al., 2015a). It is also the main cause of oncology death in women in these countries (Jemal et al., 2011). BC comprises about one-fifth of all female cancers. This cancer is the cause of deaths in high-income countries and the second cause of death in low and middle income countries (Payandeh et al., 2015b). BC is the most common cause of death in middle-aged women in developed and developing countries and its prevalence is rapidly increasing.

According to Fuladi et al study (2011) in recent years, the mortality rate of $\mathrm{BC}$ has increased rapidly in all countries. In Iran, every year 40,000 people lose their lives due to cancer and more than 70,000 new cases of cancer happens. $\mathrm{BC}$ is the most common malignancy among Iranian women (Mousavi et al., 2007). The average age of $\mathrm{BC}$ diagnosis in Iran is about 46 to 49 years (Ahmadi et al., 2015). BC has the first rank among diagnosed cancers in Iranian women. The overall mortality rate of BC during the ears 1990, 1995, 2000, 2005 and 2010 has increased from 0.96 to 4.33 per 100,000 people and also the incidence rate increased from 16.0 to 28.3 per 100,000 people during the study year (Sharifian et al., 2015). Female diseases and $\mathrm{BC}$ include $7.8 \%$ and $25.6 \%$ of all cancers in women in Iran, respectively, and these values are lower compared to other countries (Arab et al., 2013). Although Iran, with the incidence rate of 24 cases per 100,000 people, has one

${ }^{1}$ Health Promotion Research Center, Department of Epidemiology and Biostatistics, School of Public Health, Zahedan University of Medical Sciences, Zahedan, ${ }^{2}$ Students' Scientific Research Center, ${ }^{3}$ Department of Epidemiology and Biostatistics, School of Public Health, Tehran University of Medical Sciences, ${ }^{8}$ Minimally Invasive Surgery Research Center, Iran University of Medical Sciences, Tehran, ${ }^{4}$ Department of Epidemiology and Biostatistics, School of Public Health, Hamadan University of Medical Sciences, Hamadan, ${ }^{5}$ Clinical Microbiology Research Center, ${ }^{6}$ Department of Microbiology, Medical School, Ilam University of Medical Sciences, Ilam, ${ }^{7}$ Birjand University of Medical Sciences, Birjand, Iran.*For correspondence: alesaleh70@yahoo.com 
of the lowest rates of $\mathrm{BC}$ in the world, this disease is the most common cancer among Iranian women and due to the changes in risk factors and demographic pattern. BC is expected to increase sharply over the coming decades in this country (Sadjadi et al., 2009).

In Iran, BC with the frequency of $23 \%$ of women cancers is the most common form of cancer of this sex and overall, 0.9 percent of all deaths in age category of 15-49 years and 0.9 percent of all deaths in age group of 50-69 years in the country are due to BC in 2009 (Khosravi et al., 2013; Keyghobadi et al., 2015). Looking at the peak age of this cancer in Iranian women which is reported in fourth and fifth life decades reveals that it is lower than the global statistic as much as a decade (Health). Thus, after age adjusting, Iranian patients are younger and are in advanced stage of disease compared with their western counterparts as much as at least one decade (Afsharfard et al., 2013).

Despite the high prevalence of $\mathrm{BC}$ in Iranian women, the epidemiological characteristics of $\mathrm{BC}$ in Iranian patients is yet unknown (Ahmadi et al., 2015). Due to the upward trend of this cancer mortality (Taghavi et al., 2012) and based on similar patterns, it is expected that the mortality rate in Iranian women population generally increase (Haghighat et al., 2012).

Senility is considered as one of the main risk factors for this cancer. BC begins as a local disease but it can lead to lymph nodes and distant organs metastasis (Weigelt et al., 2005). Blood group, BMI, menarche age and high blood pressure are not the risk factors for $\mathrm{BC}$ alone, but probably a combination of these factors can increase the risk of BC incidence (Payandeh et al., 2015b). Known risk factors for $\mathrm{BC}$ include: age, family history, genetics, personal history of $\mathrm{BC}$, chest or face radiation before age 30, ethnicity, race, overweightness, pregnancy, breastfeeding and menstrual history, Hormone Replacement Therapy use (HRT), drinking alcohol, having dense breasts, lack of exercise, and smoking (Majeed et al., 2014).

Differences in culture, habits and ethnicity in many countries of the Eastern Mediterranean Region (such as Iran, Tunisia and Pakistan) show that the BC diagnosis age is younger than the rest of the world (Bidgoli and Azarshab, 2013). Also, some countries in the Eastern Mediterranean Region, due to lack of knowledge about $\mathrm{BC}$ screening than other regions, are in more advanced stages of cancer at diagnosis time (Harirchi et al., 2011).

The $\mathrm{BC}$ treatment varies according to the grade and stage of cancer and the patients' physical condition and demand (Yaghmaei et al., 2008). Early detection of BC plays a major role in reducing mortality and improving patients' prognosis among women (Elmore et al., 2005; Hoerger et al., 2011). So in some cancers, such as BC, long-term survival is expected to occur (Rahimzadeh et al., 2013).

Paying attention to the cancer as a health priority at national and regional levels is among the requirements of the health system. So due to the changing life patterns, proportional control of communicable diseases and increased life expectancy in Iran, it is expected that incidence of cancer will increase in the coming years. Therefore, it is necessary to examine the epidemiological
Table1. Standardized Incidence Rates of Breast Cancer in Iranian Provinces

\begin{tabular}{|c|c|c|}
\hline $\mathrm{NO}$ & Province & BC Incidence \\
\hline 1 & Ardebil & 13.4 \\
\hline 2 & Isfahan & 39.7 \\
\hline 3 & Ilam & 13.8 \\
\hline 4 & Azerbaijan-Shargi & 28.9 \\
\hline 5 & Azerbaijan-Gharbi & 16.4 \\
\hline 6 & Bushehr & 25.6 \\
\hline 7 & Tehran & 43.4 \\
\hline 8 & Chaharmahal & 20.2 \\
\hline 9 & Khorasan-Jonobi & 11.5 \\
\hline 10 & Khorasan-Markazi & 23.5 \\
\hline 11 & Khorasan-Shomali & 11.4 \\
\hline 12 & Khozestan & 32.0 \\
\hline 13 & Zanjan & 11.6 \\
\hline 14 & Semnan & 28.1 \\
\hline 15 & Sistan & 5.4 \\
\hline 16 & Fars & 36.2 \\
\hline 17 & Ghazvin & 18.4 \\
\hline 18 & Qom & 13.1 \\
\hline 19 & Kordestan & 19.0 \\
\hline 20 & Kerman & 23.0 \\
\hline 21 & Kermanshah & 25.1 \\
\hline 22 & Kohgiloye & 15.1 \\
\hline 23 & Golestan & 17.7 \\
\hline 24 & Guilan & 27.7 \\
\hline 25 & Lorestan & 19.2 \\
\hline 26 & Mazandaran & 28.0 \\
\hline 27 & Markazi & 36.6 \\
\hline 28 & Hormozgan & 11.9 \\
\hline 29 & Hamedan & 23.3 \\
\hline 30 & Yazd & 38.5 \\
\hline 31 & Total & 33.2 \\
\hline
\end{tabular}

situation of cancer in different regions of the country. So this study was done with the aim of the spatial analysis of BC incidence in Iran.

\section{Materials and Methods}

\section{The study area}

Iran is a country in the Middle-East with the area of $1,648,195$ square-kilometers, is the 18th largest country in the world and has a population of over 75 million (2011). Iran has a variety of environmental conditions in terms of length and breadth of geography, topographic diversity, and a range of altitude up to 5,671 meters above sea level. The Iranian climate varies from arid to subtropical. Iran is bordered by Armenia, Turkmenistan, and Azerbaijan to the north, (as well as by Russia and Kazakhstan via a water border in the Caspian Sea); Afghanistan and Pakistan in the east; the Persian Gulf and Gulf of Oman to the south; Iraq to the east; and Turkey to the northwest (Mostafavi 
et al., 2013). Iran is currently divided into 31 provinces.

\section{Study design and data collection}

This is an ecological study in Iran. The data were collected from Cancer Registry Center report of health deputy which is based on Iran ministry of health guideline (Goya, 2007). Data were collected retrospectively reviewing all new $\mathrm{BC}$ patients in cancer registry center report of health deputy for Iran in 2009. BC was defined as ICD-OC16. Age-standardized rates of cancer incidence were calculated by the direct standardization method, using the world standard population as a reference (Rahimi and Heidari, 2012). After data collection, information was inserted into Excel datasheets. Using Excel was justified by the faster computational capabilities and the ability to convert and store data in tables which can be linked to geographical maps in ArcGIS software, as well as it being an interactive environment for checking numbers simultaneously when entering data.

\section{Spatial analysis by GIS}

The most recent updated electronic map of Iran and its provinces was used. To link data tables to the map, a so-called ID field was created in the Excel tables reporting the incidence of BC. The code entered corresponded to the code of a province in the map data tables. The tables and map were then linked by a common field.

Identifying disease Hot-Spots was done using Getis-Ord Gi* (Spatial Statistics) (Figure 1). An Hot-Spot was defined as a province which not only has a high incidence of disease itself but also has a neighboring province with a high incidence. In otherwords, the Hot-Spots Analysis shows that provinces with high incidence of disease become a focus of disease if there is high incidence in surrounding provinces as well. To the

$$
G_{i}^{*}=\frac{\sum_{j=1}^{n} w_{i, j} x_{j}-\bar{X} \sum_{j=1}^{n} w_{i, j}}{S \sqrt{\frac{\left[n \sum_{j=1}^{n} w_{i, j}^{2}-\left(\sum_{j=1}^{n} w_{i, j}\right)^{2}\right]}{n-1}}}
$$

Figure 1. Getis-Ord Gi* (Spatial Statistics) - where $\mathrm{Xi}$ is the Attribute Value for Feature $\mathrm{j}$, wij is the Spatial Weight between Feature $i$ and $j, n$ is Equal to the Total Number of Features.

contrary, it can be said that 'Cold-Spots' are provinces with not only low incidence but also with low-incidence neighbors. Provinces that were 1.96 SD higher or lower than the national average considered as Hot Spots or Cold Spots at the level of $0.05 \%$.

\section{Results}

In 2009, a total of 7,582 cases of BC occurred in Iran. The annual incidence of $\mathrm{BC}$ was 33.2 per hundred thousand people. Our study showed that the highest Incidence of $\mathrm{BC}$ in women was for the central provinces of the country, the Provinces of Tehran with 43.4, Isfahan with 39.7, Yazd with 38.5, Markazi with 36.6 and Fars with 36.2 per hundred thousand people have shown the highest rate of incidence, respectively (Table 1).

The results of Hot Spots analysis showed that the distribution of high-risk $\mathrm{BC}$ areas is more in central provinces of the country, the Isfahan province was known as a Hot Spot for $\mathrm{BC}(\mathrm{p}<0.01)$. The other provinces were not significantly different from the national average (Figure 2).

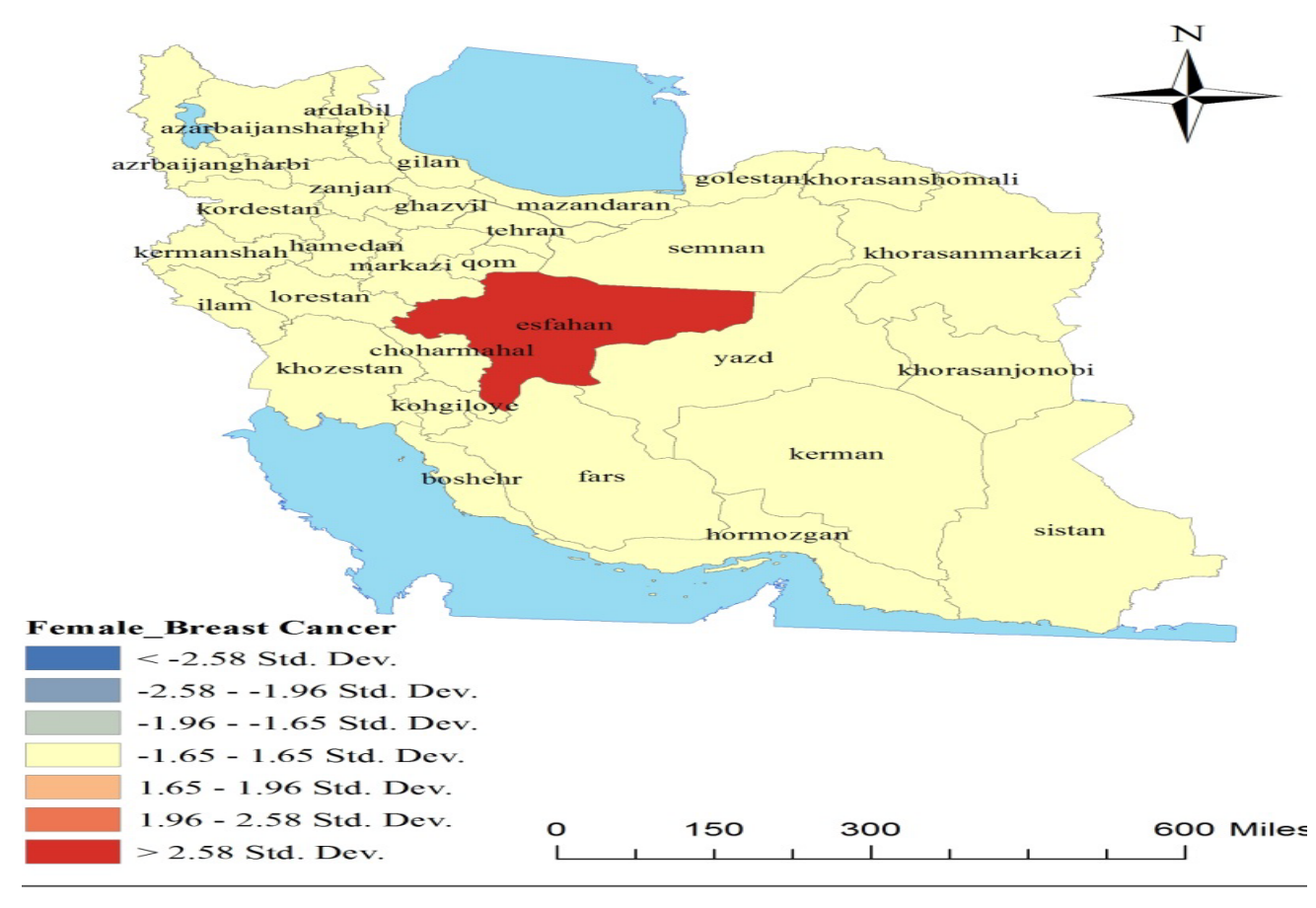

Figure 2: Hot Spots of Breast Cancer in Females in 2009 


\section{Discussion}

Iran, in the western part of Asia, faces an increased incidence of BC (Mousavi et al., 2006). According to new statistics in Iran, each year 6160 cases of BC are diagnosed that will result in 1063 deaths (Mousavi et al., 2007; Alizadeh et al., 2014).

This study showed that the highest rates of $\mathrm{BC}$ incidence in women is in central provinces such as: Tehran, Isfahan, Yazd, Markazi and Fars provinces and the lowest incidences were for the provinces Sistan and Baluchestan, Khorasan, South Khorasan and Zanjan. These results are similar to previous reported results (Mahaki et al., 2011; Jafari-Koshki et al., 2014). Also due to Hadad khoshkar et al study in model without adjustment for risk factors, the highest incidence was for the provinces of Isfahan, Yazd and Tehran and the lowest incidence was for the provinces of Sistan and Baluchestan, Chaharmahal and Bakhtiari. With usage of model with adjustment for risk factors, the highest incidence was for the provinces of Khorasan, Lorestan and Hamedan and the lowest one was for Ardabil and Kohgiluyeh and BoyerAhmad provinces.

A significant positive association between $\mathrm{BC}$ and economic-educational status was found (Mohagheghi et al., 2009; Khoshkar et al., 2015). Mohagheghi et al study in Tehran showed that socioeconomic status is an important variable in diagnosis of $\mathrm{BC}$, avoiding problems related to cancer and raising awareness about the disorder (Mohaghegh et al., 2014).

Some studies show uniformity in the incidence of this cancer. Babayi et al (2009) study in Ardebil represents a fairly steady trend in the incidence of this cancer over the years 2004-2006. Compared with sajjadi et al (2003) study in this province in years of 1996-1999 that showed increased incidence of cancer, both studies are consistent with statistics of Cancer Registry Nouri nejad and Naghibi et al $(2009,2013)$ study in Mazandaran province also showed an increasing trend in the incidence of $\mathrm{BC}$ among women in this province which is consistent with data from the Cancer Registry. Also a study in different provinces across the country showed that Isfahan has the lowest marriage rate and is located among the provinces which have high incidence of BC while Mazandaran with the highest rate of married people also is located among the risky provinces and Sistan and Baluchestan province with the lowest $\mathrm{BMI}$ is located among the provinces with low-risk BC incidence (Abbastabar et al., 2012b). Davari stated the following notes about risk factors of $\mathrm{BC}$ incidence in Yazd: "older ages, living in the city, early onset of menarche (under 14 year), late onset of menopause (over 50 years) and family history of cancer are among the most important risk factors and a history of cancer in the uterus and ovaries, thoracic radiotherapy, other side $\mathrm{BC}$ and weight over $60 \mathrm{~kg}$ are among less important risk factors which has conformity with other countries statistically. But, in this study unlike other studies in the world, being single, the first pregnancy after age 30 , having children and number of the children were not considered as risk factors for cancer and a history of benign BC was not among the risk factors unlike other studies(Abbastabar et al., 2012a).
According to a study conducted in south of Iran during the past 15 years, the lowest BC screening was in Zahedan (an eparchy in the South East of Iran) (Heidari et al., 2008), and the highest was in Tehran (Montazeri et al., 2008). Also the results of a study conducted in the city of Zabol in Sistan and Baluchestan province showed the low level of knowledge and practice about breast self-examination in people. The subjects were in a middle level of the subsets of health belief model. Also, the sensitivity perception, perceived risk, benefits and barriers, health motivation and self-confidence in BSE were higher in groups who knew and did this behavior. There was found a statistically significant relation between self-examination and positive family history of BC (Mahmood and Ramazani, 2011). Positive family history of BC is one of the main risk factors in Sabzevar city of North Khorasan Province. Due to the fact that the cancer incidence age in this city like other regions of country is a decade earlier than other countries, paying attention to early screening for women with positive family history has led to a reduction in the incidence in this province (Akbarzadeh et al., 2014).

The results of Hot-Spots Analysis in this study showed that the distribution of $\mathrm{BC}$ in high-risk areas was more in central provinces of the country, Isfahan was known as BC Hot-Spot. According to the studies conducted in 2005-2006, the BC incidence in Iranian women was 13.3\% and $10 \%$ of all BC cases are related to Isfahan (Asadpour, 2006). Mokarian et al (2011) study results showed that the incidence of cancer ( 4 per 1,000 People) in Isfahan province increased in recent years and gastrointestinal and $\mathrm{BC}$ Are pioneers in this area. There is a gender difference in the incidence of cancer and many people in middle age and with an average age of 56 years are affected. Early detection programs can lead to an increase in the incidence of $\mathrm{BC}$.

Also another study in Dehaghan city of Isfahan showed that high prevalence of $\mathrm{BC}$ risk factors in women 20 to 69 is related to people's unhealthy lifestyles that includes irregular physical activity, exposure to smokers at home and a BMI of 30 or higher (Badrian et al., 2014). Also Key et al (2001) study showed that the consumption of foods high in fat and red meat increases the risk of BC. The results of studies on the consumption of foods such as vegetables and fruits show an inverse relationship with $\mathrm{BC}$ incidence. Some studies have shown conflicting results for example, Bushehr has the highest consumption of vegetables and Mazandaran has the highest marriage rate among the provinces but in both provinces, the incidence of $\mathrm{BC}$ was high. These contradictions can be attributed to the following reasons: $1 . \mathrm{BC}$ is a multipurpose disease which develops from a combination of several risk factors. The value of a risk factor may be low in a province, but other factors value may be high in the province under study; 2. Data on the incidence of $\mathrm{BC}$ are collected from an example of each province population. Although the sample is randomly selected, it may not be representative of the total population and selection bias may have occurred (Abbastabar et al.).

The higher incidence in central provinces can be due to: air pollution, being more exposed to carcinogens in 
urban areas or due to more cancer cases diagnosis in provinces, promoted western lifestyle, and increased pollution with development of economic situation. Development of the economic situation could lead to early detection of BC Patients (Abbastabar et al.). Also the risk of $\mathrm{BC}$ in working women is higher than housewives, and it could be due to socioeconomic status, exposure to stress or occupational carcinogens (Harirchi et al., 2012). Due to the decline in total fertility rate and life style changes, the number of $\mathrm{BC}$ new cases are expected to double in 2030 (Mousavi et al., 2007). In Iran, no national screening program for $\mathrm{BC}$ is done and studies showed that women awareness of the warning and effective signs is very inadequate (Yavari and Pourhoseingholi, 2007; Montazeri et al., 2008). In addition, the health learning program for women in Iran in order to reduce the lack of women awareness about $\mathrm{BC}$ will be beneficial to control the cancer burden in the future (Sharifian et al., 2015).

The higher incidence in central provinces can be due to more exposure to carcinogens in urban areas, Western lifestyle and high prevalence of other risk factors. So further epidemiological studies about the etiology and early detection of $\mathrm{BC}$ are essential.

\section{References}

Abbastabar H, Sepandi M, Khammarnia M, et al (2012). Spatial Distribution of Breast Cancer and Its Risk Factors in the 32 Provinces of Iran.14, 1513-7368

Abbastabar H, Soleymani DM, Hamidi FP, et al (2012a). The relationship between breast cancer and the most common noncontagious disease risk factors: an ecologic study. $J$ Health Syst Res, 8, 369-76.

Abbastabar H, Soleymani DM, Hamidi FP, et al (2012b). The relationship between breast cancer and the most common non contagious disease risk factors: an ecologic study.

Abdolhasan Naghibi S, Shojaizadeh D, Montazeri A, et al (2013). Epidemiology of Breast Cancer in Mazandaran Province, 2009-2010. J Mazandaran Univ Med Sci, 23, 110-19.

Afsharfard A, Mozaffar M, Orang E, et al (2013). Trends in epidemiology, clinical and histopathological haracteristics of breast cancer in Iran: results of a 17 year study. Asian Pac $J$ Cancer Prev, 14, 6905-11

Ahmadi AS, Mahdipour L, Payandeh M, et al (2015). Epidemiology, Pathology and Histochemistry Features in Women with Breast Cancer. Ame J Cancer Prev, 3, 54-7

Akbarzadeh R, Ghardashi F, Koshki A, et al (2014). Individual characteristics, family history and blood group in with breast cancer in Sabzevar. Iran J Obstet Gynecol Infertil, 17, 109-15.

Alizadeh Oh, Hoseini M, Mirmalek A, et al (2014). Breast Sarcoma: A Review Article. Iran J Surg, 22, 1-11.

Almasi Z, Rafiemanesh H, Salehiniya H (2015). Epidemiology characteristics and trends of incidence and morphology of stomach cancer in Iran. Asian Pac J Cancer Prev, 16, 2757-61.

Arab M, Noghabaei G, Kazemi SN (2013). Comparison of crude and age-specific incidence rates of breast, ovary, endometrium and cervix cancers in Iran, 2005. Asian Pac J Cancer Prev, 15, 2461-4.

Asadpour A (2006). Isfahan: First degree of cancer in Iran. Jame Jam J, 6, 15-16.

Babaei M, Jaafarzadeh H, Sadjadi A, et al (2009). Cancer incidence and mortality in Ardabil: Report of an ongoing population-based cancer registry in Iran, 2004-2006. Iran J
Public Health, 38, 35-45.

Badrian M, Ahmadi P, Amani M, et al (2014). Prevalence of risk factors for breast cancer in 20 to 69 years old women. Iran $J$ Breast Dis, 7, 67-75

Bidgoli SA, Azarshab H (2013). Role of vitamin D deficiency and lack of sun exposure in the incidence of premenopausal breast cancer: a case control study in Sabzevar, Iran. Asian Pac J Cancer Prev, 15, 3391-6.

Elmore JG, Armstrong K, Lehman CD, et al (2005). Screening for breast cancer. Jama, 293, 1245-56.

Ghoncheh M, Mohammadian-Hafshejani A, Salehiniya H (2015). Incidence and Mortality of Breast Cancer and their Relationship to Development in Asia. Asian Pac J Cancer Prev, 16, 6081-7.

Goya M (2007). Iranian annual cancer registration report $2005 / 2006$. Ministry of health and medical education, health deputy. center for disease control and prevention, [In Persian].

Haghighat S, Akbari M, Ghaffari S, et al (2012). Standardized breast cancer mortality rate compared to the general female population of Iran. Asian Pac J Cancer Prev, 13, 5525-8.

Harirchi I, Azary S, Montazeri A, et al (2012). Literacy and breast cancer prevention: a population-based study from Iran. Asian Pac J Cancer Prev, 13, 3927-30.

Harirchi I, Kolahdoozan S, Karbakhsh M, et al (2011). Twenty years of breast cancer in Iran: downstaging without a formal screening program. Ann Oncol, 22, 93-7.

Health Mo ministry of health and medical education, noncommunicable disease control, cancer registration report for year 2008, IR of Iran, (2011).

Heidari Z, Mahmoudzadeh-Sagheb H, Sakhavar N (2008) Breast cancer screening knowledge and practice among women in southeast of Iran. Acta Med Iranica, 46, 321-8.

Hoerger TJ, Ekwueme DU, Miller JW, et al (2011). Estimated effects of the national breast and cervical breast cancer mortality. Am J Prev Med, 40, 397-404.

Jafari-Koshki T, Schmid VJ, Mahaki B (2014). Trends of breast cancer incidence in Iran during 2004-2008: a Bayesian space-time model. Asian Pac J Cancer Prev, 15, 1557-61.

Jemal A, Bray F, Center MM, et al (2011). Global cancer statistics.CA Cancer J Clin, 61, 69-90.

Key TJ, Verkasalo PK, Banks E (2001). Epidemiology of breast cancer. Lancet Oncol, 2, 133-40.

Keyghobadi N, Rafiemanesh H, Mohammadian-Hafshejani A, et al (2015). Epidemiology and trend of cancers in the province of Kerman: southeast of Iran. Asian Pac J Cancer Prev, 16, 1409-13..

Khoshkar AH, Koshki TJ, Mahaki B (2015). Comparison of bayesian spatial ecological regression models for investigating the incidence of breast cancer in Iran, 2005. Asian Pac J Cancer Prev, 16, 5669-73.

Khosravi A, Aghamohamadi S, Kazemi E, et al (2013). Mortality profile in Iran (29 provinces) over the years 2006 to 2010. Tehran: Ministry of Health and Medical Education.

Mahaki B, Mehrabi Y, Kavousi A, et al (2011). Multivariate disease mapping of seven prevalent cancers in Iran using a shared component model. Asian Pac J Cancer Prev, 12, 2353-8.

Mahmood A, Ramazani A (2011). Study of knowledge, attitude, and practice of presenting women to Zabol health centers with regard to breast self examination by Using health belief model (in 2009). Mod Care J, 8, 65-72.

Majeed W, Aslam B, Javed I, et al (2014). Breast cancer: major risk factors and recent developments in treatment. Asian Pac J Cancer Prev, 15, 3353-8.

Mohaghegh P, Yavari P, Akbari ME, et al (2014). The Correlation 
between the family levels of socioeconomic status and stage at diagnosis of breast cancer. Iran J Cancer Prev, 7, 232.

Mohagheghi MA, Mosavi-Jarrahi SA, Malekzadeh R, et al (2009). Cancer incidence in tehran metropolis: the first report from the tehran population-based cancer registry. Archives of Iranian medicine, 12, 15-23

Mokarian F, Ramezani MA, Heydari K, et al (2011). Epidemiology and trend of cancer in Isfahan 2005-2010. J Isfahan Med Sch, 16, 1228

Montazeri A, Vahdaninia M, Harirchi I, et al (2008). Breast cancer in Iran: need for greater women awareness of warning signs and effective screening methods. Asia Pac Fam Med, 7, 6-9.

Mostafavi E, Haghdoost A, Khakifirouz S, et al (2013). Spatial analysis of Crimean Congo hemorrhagic fever in Iran. Am $J$ Trop Med Hyg, 89, 1135-41

Mousavi SM, Mohaghegghi MA, Mousavi-Jerrahi SA, et al (2006). Burden of breast cancer in Iran: a study of the Tehran population based cancer registry. Asian Pac J Cancer Prev, 7, 571-4.

Mousavi SM, Montazeri A, Mohagheghi MA, et al (2007). Breast cancer in Iran: an epidemiological review. Breast $J, \mathbf{1 3}, 383-91$.

Nejad FN, Daryasari RR, Ghafari F (2009). Epidemiology of cancer in Mazandaran province 2006. J Mazandaran Univ Med Sci, 19, 61-5.

Payandeh M, Sadeghi E, Sadeghi M, et al (2015a). Different presentation of treatment in carcinomatous meningitis of breast cancer: report of 3 cases. Am J Cancer Pre, 3, 4-7.

Payandeh M, Shazad B, Sadeghi M, et al (2015b). Association between of BMI and blood groups with breast cancer incidence among women of West Iran: a case-control Study. Am J Cancer Pre, 3, 65-7.

Rahimi F, Heidari M(2012). Time trend analysis of stomach cancer incidence in the west of Iran. J Mazandaran Univ Med Sci, 19, 61-65.

Rahimzadeh M, Baghestani AR, Gohari MR, et al (2013). Estimation of the cure rate in Iranian breast cancer patients. Asian Pac J Cancer Prev, 15, 4839-42.

Rasel M, Ardalan A (2007). Ageing and future health care costs: a warning for the health system (a review article). Salmand Iran J Ageing, 2, 300-5.

Razi S, Rafiemanesh H, Ghoncheh M, et al (2015). Changing trends of types of skin cancer in Iran. Asian Pac J Cancer Prev, 16, 4955-8.

Sadjadi A, Malekzadeh R, Derakhshan MH, et al (2003). Cancer occurrence in Ardabil: Results of a population-based Cancer Registry from Iran. Int J Cancer, 107, 113-8.

Sadjadi A, Nouraie M, Ghorbani A, et al (2009). Epidemiology of breast cancer in the Islamic Republic of Iran: first results from a population-based cancer registry, 32, 259-60

Sharifian A, Pourhoseingholi MA, Emadedin M, et al (2015). Burden of breast cancer in Iranian women is increasing. Asian Pac J Cancer Prev, 16, 49-52

Taghavi A, Fazeli Z, Vahedi M, et al (2012). Increased trend of breast cancer mortality in Iran. Asian Pac J Cancer Prev, 13, 367-70

Weigelt B, Peterse JL, Van't Veer LJ (2005). Breast cancer metastasis: markers and models. Nat Rev Cancer, 5, 591-602

Yaghmaei S, Bani HG, Ghorbani R (2008). Survival rate following treatment of primary breast cancer in Semnan, Iran (1991-2002). Iran j environ health sci eng, 1, 37-44.

Yavari P, Pourhoseingholi MA (2007). Socioeconomic factors association with knowledge and practice of breast self-examination among Iranian women. Asian Pac J Cancer Prev, 8, 618-22.
Zahedi A, Rafiemanesh H, Enayatrad M, et al (2015). Incidence, trends and epidemiology of cancers in North West of Iran. Asian Pac J Cancer Prev, 16, 7189-93.

Zeinalzadeh AH, Hosseini R, Abdullahi L (2015). Survey of epidemiology of cancers in the patients above 15 years old in east Azerbaijan province, Iran 2013. J Ardabil Univ Med Sci, 15, 46-55. 